Artigos

Volume 11 - $2021 \mid$ n. 1

\title{
Os Recursos Direcionados às Crianças de 0 a 5 Anos de Idade no Contexto do Fundeb em João Pessoa/PB
}

\author{
Joedson Brito Santos \\ Universidade Federal do Tocantins (UFT), Palmas/TO - Brasil \\ Luiz de Sousa Junior \\ Universidade Federal da Paraíba (UFPB), João Pessoa/PB - Brasil
}

\section{Resumo}

$\mathrm{O}$ artigo analisa o atendimento e os recursos direcionados para as crianças de 0 a 5 anos de idade no município de João Pessoa/PB, no contexto do Fundo de Manutenção e Desenvolvimento da Educação Básica e de Valorização dos Profissionais da Educação (Fundeb), entre os anos de 2007 a 2016. A pesquisa empírica se deu a partir da produção e da análise de dados e informações em relatórios oficiais, disponíveis no Sistema de Informações sobre Orçamento Público em Educação (Siope) do Fundo Nacional de Desenvolvimento da Educação (FNDE), no Instituto Nacional de Estudos e Pesquisas Educacionais Anísio Teixeira (Inep), no TC Educa e no Instituto Brasileiro de Geografia e Estatística (IBGE). O estudo conclui que tem ocorrido uma ampliação do atendimento e uma elevação representativa dos recursos para a educação infantil (EI). Contudo, esses recursos, além de insuficientes para assegurar a expansão pública da educação infantil e fazê-la com qualidade social, mostraram-se muito inferiores aos valores investidos no ensino fundamental (EF). Ou seja, a centralidade do investimento na educação municipal permanece no EF.

Palavras-chave: Financiamento da Educação Infantil. Fundeb. Direito à educação.

\section{Resources for children from 0 to 5 years old in the context of Fundeb in João Pessoa/PB}

\section{Abstract}

The article analyzes the care and resources directed to children from 0 to 5 years of age in the city of João Pessoa/PB, in the context of the Fund for Maintenance and Development of Basic Education and Valorization of Education Professionals (Fundeb), among the years 2007 to 2016. The empirical research took place from the production and analysis of data and information in official reports, available in the Information System on Public Budget in Education (Siope) of the National Fund for Education Development (FNDE), at the National Institute for Educational Studies and Research "Anísio Teixeira", at TC Educa and at the Brazilian Institute for Geography and Statistics (IBGE). The study concludes that there has been an expansion of care and a significant increase in resources for early childhood education. However, these resources, in addition to being insufficient to ensure the public expansion of early childhood education and do it with social quality, proved to be much lower than the amounts invested in elementary education. In other words, the centrality of investment in municipal education remains in elementary education.

Keywords: Financing of Early Childhood Education. Fundeb. Right to Education. 
Os Recursos Direcionados às Crianças de 0 a 5 Anos de Idade no Contexto do Fundeb em João Pessoa/PB

\section{Introdução}

A partir da aprovação do Fundo de Manutenção e Desenvolvimento da Educação Básica e de Valorização dos Profissionais da Educação (Fundeb), em 2007, o Brasil inaugurou um novo momento na história do financiamento da educação básica. Não necessariamente por ampliar recursos públicos para a educação, mas, principalmente, por representar uma política pública que visa assegurar o direito à educação básica pública, da creche ao ensino médio, considerando todas as etapas, os tipos e as modalidades de ensino a todos os brasileiros. Além disso, por se colocar como um mecanismo importante com função de corrigir desigualdades econômicas e educacionais ao garantir recursos mínimos por aluno. Inscrevese assim, em uma lei, a ampliação da obrigatoriedade do Estado brasileiro com a garantia da educação pública.

A incorporação das matrículas da educação infantil (EI) para o recebimento de recursos desse Fundo assegurou, ainda que de forma limitada, a possibilidade da expansão do atendimento para essa etapa da educação, seja via matrícula, seja via indução de políticas e ações para assegurar a ampliação do acesso. Isso representou um novo momento na história desse segmento, mas que, todavia, exige um olhar crítico quanto à operacionalização desse mecanismo de financiamento, bem como para o surgimento e enfrentamento de novos desafios para o direito e para as políticas de El.

Assim, o presente artigo discute o atendimento e os recursos direcionados para o provimento educacional das crianças de 0 a 5 anos de idade no município de João Pessoa/PB no contexto do Fundeb, considerando o recorte temporal de 2007 a 2016. Para tanto, o trabalho apresenta aspectos característicos, estruturais e conjunturais do financiamento da educação, particularmente do Fundeb, e seu reflexo no provimento da El. Além disso, a pesquisa traz uma análise sobre o movimento e o comportamento dos indicadores de atendimento e do financiamento da El no referido município, a partir do levantamento de dados e de informações em documentos e relatórios oficiais, por meio do Instituto Nacional de Estudos e Pesquisas Educacionais Anísio Teixeira (Inep), do Instituto Brasileiro de Geografia e Estatística (IBGE) e dos Sistemas de Informações sobre Orçamentos Públicos em Educação (Siope) do Fundo Nacional de Desenvolvimento da Educação (FNDE).

\section{O financiamento da educação e os recursos para as crianças de 0 a 5 anos de idade}

O financiamento da educação brasileira possui algumas características particulares, como a existência de dispositivos constitucionais que estabelecem obrigatoriedade da existência de percentuais mínimos de recursos públicos advindos da receita dos tributos, sobretudo, dos impostos, para serem aplicados em educação pública; a criação de fundos nacionais para financiar políticas, projetos e programas suplementares; e a criação de fundos de natureza contábil para financiar os sistemas estaduais e municipais de ensino, de acordo com a razão da matrícula. Ademais, define-se por um perfil de arrecadação centralizada e de responsabilidades descentralizadas na aplicação dos recursos.

Configura-se, também, pela existência de normativo infraconstitucional que define no que devem e no que não devem ser aplicados os recursos destinados constitucionalmente para a manutenção e para o desenvolvimento do ensino, além de ser um mecanismo de 
controle social na aplicação dos fundos. Esse dispositivo define também um valor do custoaluno nacional e na destinação de percentual dos recursos para o pagamento da remuneração dos profissionais da educação. Caracteriza-se, do mesmo modo, pela insuficiência de recursos, pela irregularidade e pela fragilidade na gestão, na aplicação e na fiscalização dos recursos, como também na existência de mecanismo de desvinculação de recursos criados pelo próprio poder público, a exemplo da Desvinculação de Recursos da União (DRU) ${ }^{1}$.

Vale ressaltar que, com a aprovação da Emenda Constitucional (EC) 95/16, que instituiu o 'Novo Regime Fiscal' e que criou um teto para os gastos primários do governo, limitando-os por 20 anos ao montante gasto no ano anterior corrigido pela inflação, os gastos com a educação passam a ter como parâmetro um novo mínimo, não mais vinculado às receitas dos impostos e, em razão disso, podem sofrer drástica redução.

Quanto ao financiamento da El, historicamente, o Estado brasileiro não assumiu o atendimento educacional da criança pequena como prioridade, bem como desenvolveu um atendimento dicotômico. Por um lado, a existência de aspectos educacionais direcionados aos jardins de infância e a um modelo de pré-escola, predominantemente, de natureza pública, para as crianças das classes mais abastadas. Por outro lado, a presença de iniciativas de baixo custo, frequentemente, a cargo de instituições comunitárias, confessionais, filantrópicas, de empresas e de órgãos da assistência social, que tinham como preocupação central aspectos relativos à higiene, saúde e proteção, voltadas para crianças de 0 a 3 anos de idade, notadamente para as famílias pobres e em condição de vulnerabilidade (KUHLMANN JUNIOR, 1991).

O Estado brasileiro só começou a desenvolver ações mais sistematizadas de atenção e de educação à criança de 0 a 6 anos de idade a partir de 1930. A criação do Ministério de Educação e Saúde, o Departamento Nacional da Criança (DNCr) e as parcerias com a Unicef e com a Unesco vão marcar esse momento. Contudo, de acordo com Kramer (2003), é possível constatar que, sobretudo, a partir de 1950, passou a ser desenvolvido no Brasil um modelo de expansão do atendimento das crianças pequenas de natureza compensatória e de caráter emergencial, orientado por organismos intergovernamentais.

Campos (1992), ao analisar o financiamento para a El, considerando as décadas de 1970 e 1980, constatou carência, desperdício, instabilidade e desencontros na direção e na gestão das políticas federais de financiamento dos programas de pré-escolares e creches no País. O atendimento era de responsabilidade de várias instâncias. Na verdade, até 1989, o atendimento à El era de responsabilidade de cinco ministérios: Ministério do Trabalho, do Interior, da Justiça, da Saúde e o da Educação (BNDES) (CAMPOS; ROSEMBERG; FERREIRA, 2001).

Contudo, a partir da Constituição Federal (CF) de 1988 e da Lei de Diretrizes e Bases da Educação Nacional (LDB) (Lei 9.394 de 1996), a El ganhou maior atenção na agenda do poder público com o reconhecimento da criança como sujeito de direito e da educação como direito de todas as crianças de 0 a 6 anos de idade, com a especificação e a definição da competência administrativa prioritariamente responsável pelo seu provimento.

1 Em 2009, com a EC n 59, o efeito da DRU para a educação foi extinto progressivamente até 2011; com a EC $n^{\circ} 93 / 2016$, foi novamente prorrogada até 2023 , mas, dessa vez, sem efeito para a educação. 
Os Recursos Direcionados às Crianças de 0 a 5 Anos de Idade no Contexto do Fundeb em João Pessoa/PB

Esse processo representou um aspecto positivo do ponto de vista de pressionar o poder público municipal a assumir a responsabilidade por essa etapa da educação. Todavia, o processo de municipalização da EI não foi acompanhado de recursos suficientes para garantir condições de infraestrutura mínima e espaços adequados para o atendimento das crianças de 0 a 5 anos de idade, profissionais qualificados e recursos materiais didático-pedagógico para o trabalho com esse segmento. $O$ que resultou no aumento da responsabilidade de gestores municipais e em limitações na garantia e na ampliação do direito da criança pequena à educação.

Em dezembro de 1996 foi promulgada a Emenda Constitucional $n^{\circ} 14$, que instituiu o Fundo de Manutenção e Desenvolvimento do Ensino Fundamental e de Valorização do Magistério (Fundef). Um fundo de natureza contábil formado no âmbito de cada estado, por $15 \%$ dos $25 \%$ da receita dos principais impostos que compõem a Manutenção e Desenvolvimento do Ensino (MDE), artigo 212 da CF/88. O Fundef redistribuiu os recursos de acordo com o número de alunos matriculados no Ensino Fundamental no ano anterior, considerando o valor por aluno mínimo anual nacional definido pelo Ministério da Educação. Essa política teve vigência até dezembro de 2006.

Apesar dos aspectos positivos, esse Fundo apresentou inúmeros pontos negativos e limitadores de seus objetivos, como a focalização do financiamento no EF, que deixou de fora as outras etapas e modalidades da educação, a exemplo, da Educação Infantil. O Fundef não conseguiu promover distribuição equitativa dos recursos, nem teve grandes impactos na redução das desigualdades entre estados e municípios. Verificaram-se, também, dificuldades na realização da fiscalização e no controle social, continuando a existir presença de manobras na contabilização da matrícula e no sentido de desvincular recursos da educação. Constatouse a presença de um Estado minimalista na complementação da União, não havendo recursos novos para além dos que já estavam constitucionalmente definidos.

O Fundef, contudo, não direcionou recursos específico para esse segmento. Tal situação provocou um abandono da El por parte daquelas redes estaduais, que também atendiam a EI (PINTO, 2018), e promoveu, em muitos municípios, um retrocesso nas matrículas da pré-escola. Segundo Didonet (2006), muitos municípios, que já investiam nessa faixa etária, ao verem retidos $15 \%$ de recursos do Fundo de Participação dos Municípios (FPM) e do repasse do ICMS ao Fundo estadual do ensino fundamental, ficaram sem dinheiro para manter a El.

De acordo com Pinto (2018), esperava-se ocorrer uma redução no crescimento das matrículas da El, mas isso "não aconteceu". Os dados do Censo Escolar de 1997 a 2007 revelam uma expansão de $354 \%$. Esse aumento se deve a diversos fatores, como a melhora na contabilização dos dados da El, o aumento da demanda da maior pressão por vagas, o novo papel do Ministério Público, bem como a luta de movimentos sociais, entidades e profissionais da educação em torno do tema. Esse crescimento, todavia, deu-se num cenário de restrições econômicas e de reforma do estado, portanto, em detrimento da qualidade ${ }^{2}$ e do fortalecimento do atendimento no setor privado ${ }^{3}$. Todos esses aspectos contribuíram para

2 Ver Campos, Füllgraf e Wiggers (2006).

3 Ver Adrião, Borghi e Domiciano (2010). 
Os Recursos Direcionados às Crianças de 0 a 5 Anos de Idade no Contexto do Fundeb em João Pessoa/PB

uma ampliação das preocupações em torno da criação de fontes de financiamento da $\mathrm{El}$, o que veio a ocorrer com o Fundeb.

\section{Financiamento da Educação Infantil no Fundeb}

Desse modo, com o objetivo de corrigir as limitações e falhas do Fundef, e após longo período de debates e negociações ${ }^{4}$, foi instituído o Fundeb pela Emenda Constitucional (EC) $n^{\circ} 53 / 2006$ e regulamentado pela Lei $n^{\circ} 11.494$ de 2007 . O Fundeb passou a subvincular $20 \%$, dos $25 \%$ da receita resultante de impostos, provenientes de transferências, para a manutenção e para o desenvolvimento do ensino, já vinculados constitucionalmente nos termos do artigo 212 da CF/88, para serem aplicados em toda Educação Básica. Desses 20\%, no mínimo $60 \%$ devem ser aplicados na Valorização dos Profissionais da Educação Básica e o restante, no máximo de $40 \%$, devem ser aplicados na MDE. O Fundeb prevê ainda a instituição de um Piso Salarial Profissional Nacional (PSPN) para os profissionais da educação. A distribuição dos recursos obedece a mesma dinâmica existente no Fundef, isto é, a partir do número de matrícula de cada rede escolar e seus respectivos entes federados responsáveis. Além disso, foi estabelecido um novo modelo para a distribuição dos recursos do Fundo por nível, etapa e modalidade de ensino intitulado fator de ponderação 5 .

Com o Fundeb, ocorreu um aumento do comprometimento da União com a universalização e a qualidade da educação básica, por meio da ampliação de parcela de complementação da União aos estados que não conseguirem atingir o valor mínimo anual que deve ser investido por aluno. A implementação do Fundeb, diferente do Fundef, foi de forma gradual, alcançando sua completude no ano de 2009 e a complementação da União passou a ser $10 \%$ sobre o valor total do Fundeb.

Com a inclusão da El para o recebimento de recursos públicos vinculados ao Fundeb, temos um processo de reafirmação da importância e do lugar da El enquanto primeira etapa da educação básica e direito das crianças de 0 a 5 anos de idade. Nesse contexto, foi possível verificar uma ampliação do atendimento da $\mathrm{El}$, tanto em creche quanto na pré-escola, conforme estudos e pesquisas de Bassi (2011) e Santos (2015).

Segundo dados do IBGE, em 2007, o país contava com aproximadamente 11,2 milhões de crianças de 0 a 3 anos de idade e somente $17,1 \%$ destas frequentavam a creche. Em relação às crianças de 4 a 5 anos, 70,1\% estavam matriculadas. A implantação do Fundeb representou, sem dúvida, um avanço para o segmento da $\mathrm{El}$, o que pode ser confirmado com a constatação da significativa ampliação da cobertura refletida em um crescimento total das matrículas em creche e pré-escolas, que passaram de 6.509.868, em 2007, para 8.745.148, em 2018, um crescimento de $34,5 \%$.

Esse crescimento continua tendo como grande protagonista o aumento das matrículas de creche. As matrículas da pré-escola mantêm-se estáveis, com alta de 3,7\%, entre os anos de 2014 e 2018, enquanto as matrículas em creche aumentaram em 23,8\% no mesmo período. Dados do relatório do Censo Escolar de 2018 indicam que, dos 115.195 estabelecimentos da El espalhados em todo o País, 81.520 pertencem à rede municipal;

\footnotetext{
4 Nesse contexto, teve papel importante o "Movimento Fundeb pra Valer", criado em 2005 e coordenado pela Campanha Nacional pelo Direito à Educação.

5 Os fatores são definidos pela Comissão Intergovernamental de Financiamento para a Educação Básica de Qualidade. Ver Lei n 11.494, de 20 de julho de 2007.
} 
Os Recursos Direcionados às Crianças de 0 a 5 Anos de Idade no Contexto do Fundeb em João Pessoa/PB

32.810 à rede privada; 842 à rede estadual; e 23 à rede federal. Esse total de estabelecimentos conta com 589.893 docentes. Em 2010, o Brasil tinha 114.216 estabelecimentos de El e 381.417 profissionais atuando nesse segmento.

Não obstante, a expansão da El vem ocorrendo de forma desigual, penalizando as crianças mais novas e de famílias de baixa renda; a população negra; os indígenas; e os que vivem no meio rural (BRASIL, 2016; 2018b; CAMPANHA, 2019). Ademais, apresenta fortes desafios na melhoria na qualidade do atendimento, principalmente para o segmento de 0 a 3 anos de idade, que aparece sempre em situação mais precária, seja em relação à formação do pessoal, seja em relação à infraestrutura (CAMPOS, 2006). O relatório da Campanha Nacional pelo Direito à Educação (2019), relativo aos primeiros 5 anos do PNE (2014), ao tratar da meta 1, apontou, por exemplo, que apenas 40,4\% das escolas de El "contavam com biblioteca/sala de leitura; $46,9 \%$ possuíam banheiros adaptados para a El; $87,1 \%$ tinham água potável; e 44,6\% possuíam parque infantil" (CAMPANHA, 2019, p. 21). Além disso, deve-se considerar a forte indução das matrículas no setor privado nesse segmento (ADRIÃO; BORGHI; DOMICIANO, 2010). Nos dados do Censo escolar de 1997 a 2018, por exemplo, podemos observar que, em 1997, a matrícula privada era de 987,432; em 2007, foi de 1.030.192; e, em 2018, chegou a 2.423.233, abarcando cerca de $27,7 \%$ do total das matrículas.

Algumas limitações do Fundeb têm impactos no financiamento da El e se constituem entraves para sua expansão com qualidade, como a quantidade insuficiente de recursos novos; os baixos fatores de ponderação para distribuição dos recursos, que são inferiores ao custo real desse atendimento; a admissão da distribuição dos recursos para matrículas de creche e de pré-escola na rede conveniada sem fins lucrativos; e a omissão quanto ao Custo Aluno Qualidade inicial (CAQi) (PINTO, 2007; 2018).

\section{$O$ atendimento das crianças de 0 a 5 anos de idade em João Pessoa/PB e o seu financiamento}

Para compreensão e análise do atendimento e dos recursos direcionados para o financiamento da El no município de João Pessoa/PB, no contexto do Fundeb, utilizamos o recorte temporal de 2007 a 2016, por representar um período de 10 anos da criação e vigência do Fundeb. A escolha de estudar o tema em tela no município de João Pessoa se deu por variados fatores, dentre eles: esse município fez uma opção declarada em dar maior atenção para a El, colocando, no Plano de Governo (2013-2016), entre seus objetivos, expandir a rede municipal, com "especial atenção às atividades das creches e da pré-escola"[...], fazendo "do acesso à El, sobretudo, o berçário, a mais alta prioridade da PMJP" e "dotando cada bairro e comunidade de pelo menos, uma creche" (JOÃO PESSOA, 2013, p. 33-34). O município também passou por um processo de municipalização da El entre 2012 e 2014 . João Pessoa/PB é o $8^{\circ}$ município mais populoso do Nordeste com a $6^{a}$ maior região metropolitana.

Nos relatórios do Censo Escolar entre 2007 e 2016, constata-se que a rede municipal de João Pessoa apresentou um decréscimo no quantitativo geral das matrículas, passando de 64.408 para 58.048 alunos matriculados. Uma redução em 6.360 matrículas e uma variação de $-09,87 \%$. No entanto, é possível observarmos uma leve retomada de crescimento entre os anos de 2012 e 2014, como pode ser verificado na Tabela 1. 
Os Recursos Direcionados às Crianças de 0 a 5 Anos de Idade no Contexto do Fundeb em João Pessoa/PB

Tabela 1 - Matrículas da rede pública municipal de Educação João Pessoa

\begin{tabular}{lllllllllll}
\hline Ano & $\mathbf{2 0 0 7}$ & $\mathbf{2 0 0 8}$ & $\mathbf{2 0 0 9}$ & $\mathbf{2 0 1 0}$ & $\mathbf{2 0 1 1}$ & $\mathbf{2 0 1 2}$ & $\mathbf{2 0 1 3}$ & $\mathbf{2 0 1 4}$ & $\mathbf{2 0 1 5}$ & $\mathbf{2 0 1 6}$ \\
\hline Mat. & 64.408 & 65.502 & 61.091 & 57.117 & 55.029 & 57.791 & 58.865 & 59.755 & 58.192 & 58.048 \\
\hline \multicolumn{8}{c}{ Fonte: Elaboração dos autores com base em Censo Escolar/Inep/MEC (2007-2016). }
\end{tabular}

Esse processo de decréscimo na matrícula não sofreu alteração, mesmo com a criação do Fundeb, que, a partir de 2007, passou a vincular recursos públicos para toda a educação básica. Ele reflete uma tendência nacional de adequação na distribuição das matrículas da educação básica, por modalidades e etapas de ensino, observada desde 2007, e aponta para um processo de acomodação do sistema educacional, que reflete a maturação de ações, de políticas e de programas implementados nos últimos anos (BRASIL, 2014). Ele também é impactado pelo fenômeno demográfico de desaceleração do crescimento populacional, seja pela redução da taxa de fecundidade, seja pela diminuição na taxa de natalidade e de modalidade infantil.

Todavia, considerando o período de investigação (2007 a 2016), o segmento da El tem apresentado movimento contrário com um significativo acréscimo no quantitativo das matrículas, sobretudo no segmento creche. Ao consultar os dados dos censos escolares (2007 a 2016), é possível constatar que houve um aumento da matrícula, tanto no âmbito nacional $(27,1 \%)$, quanto no estado da Paraíba $(17,45)$ e na rede municipal de João Pessoa $(91,41 \%)$. No caso específico de João Pessoa, a evolução das matrículas apresentou-se conforme a Tabela 2, abaixo:

Tabela 2 - Matrícula da Educação Infantil de João Pessoa/PB (2007 a 2016)

\begin{tabular}{|c|c|c|c|c|c|c|c|c|c|c|c|c|}
\hline \multirow{2}{*}{ Ano } & \multicolumn{4}{|c|}{ Creche } & \multicolumn{7}{|c|}{ Préescola } & \multirow{2}{*}{$\begin{array}{l}\text { Total } \\
\text { Geral }\end{array}$} \\
\hline & Federal & Estadual & Municipal & Privada & Total & Federal & Estadual & Municipal & Privada & Total & $\begin{array}{c}\text { T. } \\
\text { Pública* }\end{array}$ & \\
\hline 2007 & 0 & 1.274 & 1.871 & 473 & 3.618 & 3 & 2.487 & 2.718 & 2.675 & 7.883 & 8.353 & 11.501 \\
\hline 2010 & 37 & 1.173 & 1.969 & 1.672 & 4.851 & 50 & 729 & 3.426 & 5.448 & 9.653 & 7.384 & 14.504 \\
\hline 2013 & 49 & 0 & 3.844 & 3.253 & 7.069 & 57 & 15 & 4.572 & 7.803 & 12.448 & 8.537 & 19.517 \\
\hline 2016 & 40 & 0 & 5.456 & 3.187 & 8.683 & 56 & 0 & 5.299 & 7.976 & 13.331 & 10.851 & 22.014 \\
\hline Diferença** & 40 & -1.274 & 3.585 & 2.714 & 5.065 & 53 & -2.487 & 2.581 & 5.301 & 5.448 & 2.498 & 10.513 \\
\hline $\begin{array}{c}\text { Variação } \\
(\%)^{\star \star \star}\end{array}$ & - & -100 & $191,6 \%$ & $573,7 \%$ & $140 \%$ & $1.766,6 \%$ & -100 & $94,96 \%$ & $198,17 \%$ & $69,11 \%$ & $29,90 \%$ & $91,41 \%$ \\
\hline
\end{tabular}

Fonte: Elaboração dos autores com base em Censo Escolar/Inep/MEC (2007-2016). *Total de matrículas na rede pública. *Diferença: 2006-2016. **Variação: 2006-2016.

Nesse contexto, a rede privada teve um salto expressivo, pois era responsável por $27,37 \%$ do total das matrículas de El, em 2007, e, em 2016, saltou para 50,7\%, atendendo um quantitativo de 11.163 crianças. As matrículas para creche no setor privado tiveram uma elevação representativa, no período estudado, passando de 473 matrículas para 3.187, com um acréscimo de 2.714 matrículas e uma variação de $573,7 \%$. Na pré-escola, o salto também foi significativo, com uma variação de $198,17 \%$, no período em análise, passando de 2.675 para 7.976, o que corresponde a um aumento de 5.301 novas matrículas. Tanto na creche quanto na pré-escola, a variação das matrículas privadas foi superior às públicas. Podemos observar, por exemplo, que, mesmo em quantidade, o acréscimo de matrículas na creche pública tem sido numericamente maior que na privada, atingindo o valor de 3.585 e uma variação de $191,6 \%$ no período. No entanto, quanto a isso, a creche privada tem uma variação muito superior, conforme já apontado. O mesmo ocorreu com a pré-escola. 
Assim, no setor público ou no privado 6 , a El tem apresentado uma forte elevação no número de vagas e o segmento de 0 a 3 anos mostra que o crescimento da matrícula tem ficado mais perceptível. Já na pré-escola, houve uma elevação moderada e menor de matrículas em comparação à creche, porém estável, haja vista que, a partir de 2006, parte da população de 6 anos de idade deixou de ser contada na pré-escola e passou a somar nas matrículas do EF em decorrência da Lei $n^{\circ} 11.114 / 2005$ e da Lei $n^{\circ} 11.274 / 2006$, que alteraram a LDB e criaram o ensino fundamental de 9 anos $^{7}$.

A análise da taxa de atendimento da El no Brasil, no estado da Paraíba e no município de João Pessoa, a partir de dados da plataforma do TC Educa ${ }^{8}$, permite constatar que os percentuais de atendimento estão inferiores à meta 1 do PNE e muito distantes de serem alcançados. No TC Educa, as taxas de atendimento em creche, para o ano de 2016, foram, respectivamente: $28,58 \%$; $19,48 \%$; e $20,61 \%$. Já para a pré-escola, foram $80,41 \% ; 70,11 \%$; e $54,94 \%$

Apesar da ampliação da cobertura da El em todo o País, a taxa de atendimento é muito pequena, considerando o tamanho da população de 0 a 5 anos de idade e o aumento da demanda. Quando analisamos mais detalhadamente a taxa de atendimento da El em João Pessoa, constatamos que houve uma elevação em sua taxa, na qual a cobertura é muito baixa e que existem muitas crianças fora da escola. Se compararmos os dados do Censo Populacional do IBGE de 2010 com os dados do TC Educa para o ano de 2016, observaremos que houve um aumento na taxa de atendimento educacional das crianças de 0 a 5 anos de idade, em $8 \%$, passando de $24 \%$ para $32 \%$. O percentual de atendimento de crianças de $4 \mathrm{e}$ 5 anos saltou de $47 \%$ para $54,9 \%$ e, das crianças de 0 a 3 , saltou de 12 para $20,6 \%$. Contudo, é importante observar que, apesar de ter passado seis anos desde o censo de 2010, a quantidade da população de crianças com idade de 4 e 5 anos aumentou apenas em 260, em 2016. Já a quantidade de crianças de 0 a 3, aumentou em 1.011. É possível observar que, em 2016, 42.127 crianças de 0 a 5 anos estavam fora da escola, sendo 32.764 só de crianças de 0 a 3 anos de idade e 9.363 em idade de 4 e 5 anos. Ver Tabela 3.

Tabela 3 - Taxa de atendimento educacional de crianças de 0 a 5 anos de idade (2010 e 2016)

\begin{tabular}{|c|c|c|c|c|c|}
\hline Ano & Faixa etária & Total população & $\begin{array}{c}\text { Crianças } \\
\text { matriculadas }\end{array}$ & $\begin{array}{c}\text { Criança fora da } \\
\text { escola }\end{array}$ & Taxa de atendimento \\
\hline \multirow[t]{3}{*}{2010} & 4 e 5 & 20.520 & 9.653 & 10.867 & $47,05 \%$ \\
\hline & 0 a 3 & 40.261 & 4.851 & 30.608 & $12,40 \%$ \\
\hline & 0 a 5 & 60.781 & 14.504 & 41.475 & $24 \%$ \\
\hline \multirow[t]{3}{*}{2016} & 4 e 5 & 20.780 & 11.417 & 9.363 & $54,94 \%$ \\
\hline & 0 a 3 & 41.272 & 8.508 & 32.764 & $20,61 \%$ \\
\hline & 0 a 5 & 62.052 & 19.925 & 42.127 & $32 \%$ \\
\hline
\end{tabular}

Fonte: Elaboração dos autores com base nos dados do IBGE e do TC Educa. Ver: https://pne.tce.mg.gov.br:8443/\#/public/dados.

É imprescindível destacar que essa ampliação da cobertura da El é resultado de variados fatores que envolvem, desde o aumento da demanda e o crescimento da pressão por vagas, à forte atuação dos movimentos sociais em prol da garantia do direito à El. Sobre esse aspecto, é importante dizer que o Ministério Público da Paraíba (MPPB) teve um papel

6 Para uma análise pormenorizada das matrículas da EI no Brasil, consultar Santos (2015).

7 Tais mudanças são inseridas no texto constitucional na EC 53/2007.

8 Sistema de acompanhamento das metas do Plano Nacional criado pelos Tribunais de Contas Estaduais e que cruza dados do censo escolar com as estimativas populacionais do Datasus. 
importante no processo de municipalização da El em João Pessoa, pois, além de atuar no monitoramento sobre as condições de atendimento da El, em 2012 moveu uma Ação Civil na $1^{\text {a }}$. Vara da Infância contra o município pelo fato de este ter "se eximido da obrigação constitucional de municipalizar a educação infantil". Por meio dessa ação, o município foi obrigado a assumir as crianças matriculadas nas 27 creches que ainda se encontravam sob a responsabilidade do estado (PEREIRA, 2012, p. 161). Contudo, a gestão que assumiu a administração municipal e educacional a partir de 2013 já vislumbrava tal municipalização e criou as condições minimamente adequadas para a transferência das unidades de educação infantil para o município (SOUSA JUNIOR, 2017).

O processo de municipalização da $\mathrm{EI}^{9}$ ocorreu de forma gradual e concretizou-se em 2014. Nesse ano, um total de 27 escolas de El, que estavam sob a responsabilidade do estado, passaram para a administração do município. Até 2012, o município tinha 43 Centros de Referência de Educação Infantil (Creis) e chegou, ao final de 2014, com 71, pois além daquelas instituições que foram municipalizadas, o município inaugurou um novo Crei em 2014. O município fez, ainda, um reordenamento em algumas creches, resultando na oferta de mais 200 vagas na El.

Contudo, parte dessa expansão deveu-se também à criação de dispositivos legais que impactaram diretamente na ampliação do atendimento da El e políticas públicas direcionadas para o segmento infantil da educação, a exemplo do Programa Nacional de Reestruturação e Aquisição de Equipamentos para a Rede Escolar Pública de Educação Infantil (Proinfância) e o Programa Brasil Carinhoso. No caso do Proinfância, por exemplo, informações disponíveis no portal do FNDE apontam para a construção de 15 novos Creis, em João Pessoa, entre os anos de 2013 e 2018.

Desse modo, é imprescindível afirmar que não há como assegurar o direito à educação nem ampliar o atendimento da El sem a garantia de recursos mínimos para seu provimento. A garantia do direito à educação infantil não se faz apenas mediante a criação de dispositivos legais e jurídicos, mas mediante a criação de política pública social que assegure recursos públicos e financeiros para sua operacionalização. Desse modo, consideramos que, assim como o Fundef impulsionou o processo de municipalização e universalização do EF, o Fundeb tem impulsionado a ampliação da expansão da El e, particularmente, a municipalização das creches naqueles municípios que ainda não o haviam realizado, como é o caso de João Pessoa.

\section{Recursos para educação pública em João Pessoa}

A introdução da El numa política de financiamento tem indicado a presença de mais recursos para essa faixa etária. Isso pode ser verificado nos relatórios orçamentários, nas prestações de contas e nos indicadores do investimento em educação, disponíveis em relatórios municipais, estaduais e nacionais no Siope/FNDE, no Inep/MEC, dentre outras fontes. Nesse cenário, é possível constatar que, em consonância com o crescimento do

9 O processo de municipalização da El em João Pessoa ocorreu de forma gradual. O primeiro em 1999, com a passagem da El da Secretaria de Desenvolvimento Social para a Secretaria de Educação e Cultura Municipal, mas muitas instituições ainda ficaram sob a responsabilidade do estado. O segundo, foi o processo de transferência das instituições que estavam sob a administração do estado para a administração municipal, que começou em 2006, foi retomado em 2012 e concluído em 2014. Ver Santos (2015). 
Os Recursos Direcionados às Crianças de 0 a 5 Anos de Idade no Contexto do Fundeb em João Pessoa/PB

investimento em educação, ocorrido entre os anos de 2007 a 2016, particularmente, no contexto da implementação do Fundeb, a El também tem apresentado aumento de seus indicadores de atendimento/cobertura e de recursos.

No que se refere ao percentual do investimento em educação, dados do FNDE/MEC e do Inep/MEC (2016) revelam que o investimento público total em El, que, desde o início dos anos 2000 estava a $0,3 \%$ do PIB, chegou em 2015 ao valor de $0,7 \%$, e o percentual do investimento direto nesse segmento alcançou, em 2016, 0,6\%. Já a estimativa nacional do valor do investimento público total por aluno dessa etapa da educação passou de R\$1.950 para 6.443 em 2015. O aumento de $0,4 \%$ para $0,7 \%$ é um acréscimo representativo em valores, uma vez que se trata de pontos percentuais relativos ao PIB brasileiro. Além disso, é um aumento que está dentro da média dos países da Organização para a Cooperação e Desenvolvimento Econômico (OCDE), pois, de acordo com o relatório Glance (2018), todos os países da OCDE ampliaram os gastos com a pré-escola em relação ao PIB, entre 2005 e 2015 , em pelo menos 0,3 pontos percentuais. O Chile, por exemplo, passou de $0,5 \%$ para $0,8 \%$, a Coreia do Sul saltou de $0,1 \%$ para $0,6 \%$, enquanto o Brasil passou de $0,4 \%$ para $0,7 \%$ (BRASIL, 2018a). Porém, no caso brasileiro, o percentual de investimento é muito baixo, considerando os custos reais desse segmento, as demandas de expansão para o alcance da Meta 1 do PNE 2014-2024 e os critérios de acesso, equidade e qualidade presentes nas 17 estratégias dessa Meta.

No que se refere ao município de João Pessoa, também é possível identificar um aumento dos recursos para o segmento da El entre os anos de 2007 a 2016. Para analisarmos esses recursos tomamos como base os gastos com MDE, com o Fundeb e com a Subfunção Educação Infantil (365). Cabe destacar que a ausência e a qualidade dos dados por vezes dificultam a análise dos recursos públicos aplicados na El, haja vista, historicamente, existirem problemas e limitações quanto ao alcance dos valores exatos aplicado no atendimento à infância. De acordo com Campos (1992, p. 17), por exemplo, em geral, os dados sobre o financiamento da infância sempre estavam agregados em categorias maiores, "espalhadas por subprogramas" ou localizadas em grandes funções. Atualmente alguns dados têm sido apresentados de forma mais detalhada, o que melhora a qualidade das informações, mas ainda há muito o que avançar nesse aspecto.

Os gastos em MDE na El em João Pessoa, entre os anos de 2007 e 2016, apresentaram aumento expressivo, de aproximadamente $740 \%$, em valores corrigidos no período, e sua participação saltou de $2,44 \%$ para $11,62 \%$. Ainda assim, segundo a Tabela 4 , os recursos aplicados no EF continuaram elevados.

Tabela 4 - Gasto e aplicação com MDE na El e no EF em João Pessoa em 2007 e 2016 (R\$)

\begin{tabular}{crrrrr}
\hline & $\mathbf{2 0 0 7}$ & $\mathbf{2 0 1 0}$ & $\mathbf{2 0 1 3}$ & $\mathbf{2 0 1 6}$ & \multicolumn{1}{c}{ Variação } \\
\cline { 3 - 6 } & & & & $\mathbf{2 0 0 7 / 2 0 1 6}$ \\
\hline EI & $5.245 .585,52$ & $8.977 .505,70$ & $28.601 .111,10$ & $43.873 .527,73$ & 736,4 \\
\hline (\%) & 2,44 & 2,75 & 7,54 & $11,62 \%$ & \\
\hline EF & $209.927 .458,66$ & $318.923 .768,52$ & $350.960 .126,47$ & $333.720 .663,92$ & 59,0 \\
\hline$(\%)$ & 97,56 & 97,56 & 92,46 & $88,38 \%$ & \\
\hline Total & $215.173 .044,18$ & $326.892 .911,35$ & $379.561 .237,57$ & $377.594 .191,65$ & 75,5
\end{tabular}

Fonte: Elaboração dos autores com base no Relatório Resumido da Execução Orçamentária/Siope/FNDE. Valores corrigidos pelo INPC de janeiro de 2016. 
Os Recursos Direcionados às Crianças de 0 a 5 Anos de Idade no Contexto do Fundeb em João Pessoa/PB

Ao lançamos o olhar, particularmente, para os recursos do Fundeb, entre os anos de 2007 e 2016, constatamos uma elevação expressiva dos recursos advindos dessa política de fundo público, tanto em relação aos recursos de fontes estadual e municipais quanto em relação à complementação da União para esse Fundo. Desse modo, no período de 2007 a 2016, as receitas do Fundeb praticamente dobraram em valores reais, saltando de $R \$$ 105.723.835,17 para $\mathrm{R} \$ 1$ 199.222.162,3.

Quando analisamos o percentual do Fundeb aplicado em El, entre os anos de 2007 a 2016, constatamos, também, que houve aumento significativo dos recursos do Fundeb para esse segmento, que saltou de $0,19 \%$ para $13,99 \%$. No entanto, trata-se de valores e percentuais muito baixos quando comparados ao valor absoluto das despesas com esse Fundo em 2016, como também com as necessidades de expansão e de qualidade. Verificamos, também, que a aplicação dos recursos do Fundeb se concentra quase que na sua totalidade no EF. Em 2007, por exemplo, mais de 99,80\% dos recursos do Fundeb foram direcionados para o EF, em 2016 esse percentual diminuiu para $87,22 \%$, conforme apontado na Tabela 5:

Tabela 5 - Aplicação dos recursos do Fundeb na El e no EF em João Pessoa (2007 e 2016) (R\$)

\begin{tabular}{|c|c|c|c|c|c|c|}
\hline & 2007 & 2010 & 2013 & 2016 & $\begin{array}{c}\text { Variação } \\
07 / 16\end{array}$ & $\begin{array}{c}\text { Diferença } \\
07 / 16\end{array}$ \\
\hline Fun/ El (a) & $165.705,57$ & $2.917 .550,42$ & $26.573 .175,62$ & $27.413 .956,40$ & $1644377,50 \%$ & $27.248 .250,83$ \\
\hline$(\%) a / c$ & $0,19 \%$ & $2,19 \%$ & $15,63 \%$ & $14,00 \%$ & & \\
\hline Fun/ EF (b) & $86.098 .280,33$ & $129.404 .463,55$ & $143.426 .465,43$ & $168.554 .874,00$ & $9577,03 \%$ & $82.456 .593,67$ \\
\hline$(\%) b / c$ & $99,81 \%$ & $97,80 \%$ & $84,37 \%$ & $86,00 \%$ & & \\
\hline Fun/Total (c) & $86.263 .985,90$ & $132.322 .013,98$ & 169.999.641,05 & $195.968 .830,40$ & $12717,34 \%$ & $109.704 .844,50$ \\
\hline
\end{tabular}

Fonte: Elaboração dos autores com base no Relatório Resumido da Execução Orçamentária/Siope/FNDE. Valores corrigidos pelo INPC de janeiro de 2016.

Ao analisarmos as despesas relativas à Subfunção Educação Infantil (Código 365) ${ }^{10}$, em João Pessoa/PB, nos demonstrativos da Função Educação no Siope/FNDE, constatamos que o município gastou um volume total de $\mathrm{R} \$ 192.443 .567,095$ com a Função Educação, em 2007, e, desse valor, aplicou $\mathrm{R} \$ 2.328 .331,70$ com a subfunção (365), ou seja, o equivalente a $1 \%$. Por outro lado, em 2016 , esse percentual subiu para quase $10 \%$, segundo a Tabela 6 :

Tabela 6 - Demonstrativo da Função Educação em João Pessoa/PB, em 2007 e 2016

\begin{tabular}{lrr}
\hline \multicolumn{1}{c}{ Subfunções } & Despesas pagas R\$ & $\mathbf{2 0 0 7}$ \\
\hline $\mathbf{3 6 1}$ - Ensino Fundamental & $190.115 .235,39$ & $\mathbf{2 0 1 6}$ \\
\hline $\mathbf{3 6 5}$ - Educação Infantil & $2.328 .331,70$ & $\mathbf{2 9 1 . 8 6 8 . 3 9 6 , 4 8}$ \\
\hline Total da Função Educação & $192.443 .567,09$ & $38.496 .811,56$ \\
\hline
\end{tabular}

Fonte: Elaboração dos autores com base nos demonstrativos da função educação no Siope/FNDE. Valores corrigidos pelo INPC de 2016.

Em 2016, passados dez anos da inclusão da educação no Fundeb, João Pessoa/PB utilizou $\mathrm{R} \$ 387.005 .386,70$ com despesas pagas com a Função Educação. Desse volume, utilizou um total de $\mathrm{R} \$ 291.868 .396,48$ com o EF, ou seja, $75,4 \%$. Em 2007, o percentual de gasto com EF foi praticamente de $99 \%$. As despesas totais pagas com a El em relação às aplicadas com a Função Educação passaram de $\mathrm{R} \$ 2.328 .331,70$, em 2007, para $\mathrm{R} \$$ 38.496.811,56, em 2016, uma elevação de mais de $\mathrm{R} \$ 36$ milhões. Desse valor, no ano de 2016, a quantia de $R \$ 21.423 .868,41$ foi gasta com o segmento creche e, $R \$ 17.072 .943,15$,

10 Nos gastos com a subfunção (365) estão embutidas as receitas vinculadas e as outras da Educação, como, por exemplo, o recurso da merenda escolar, do salário-educação e de projetos específicos para essa etapa. 
Os Recursos Direcionados às Crianças de 0 a 5 Anos de Idade no Contexto do Fundeb em João Pessoa/PB

com a pré-escola. Esse movimento, de elevação no quantitativo dos recursos, representou um salto de 1,16\% para 10\%, no percentual de aplicação da subfunção (365), em relação ao montante dos gastos com a Função Educação. Ver na Tabela 7 os valores aplicados na subfunção educação infantil (365) distribuídos entre creche e pré-escola.

Tabela 7 - Despesas relativas à subfunção educação infantil (365) em João Pessoa/PB, em 2007-2016

\begin{tabular}{|c|c|c|c|c|}
\hline Ano & & Empenhadas (em R\$) & Liquidadas (em $\mathbf{R} \$$ ) & Pagas (em R\$) \\
\hline \multirow[t]{2}{*}{2007} & Creche & $8.065 .758,54$ & $3.423 .403,23$ & $2.328 .331,70$ \\
\hline & Pré-escola & & & \\
\hline \multirow{2}{*}{2008} & Creche & $6.560 .179,72$ & $4.939 .388,93$ & $4.939 .388,93$ \\
\hline & Pré-escola & & & \\
\hline \multirow[t]{2}{*}{2009} & Creche & $2.216 .628,74$ & $2.207 .975,16$ & $2.207 .975,16$ \\
\hline & Pré-escola & & & \\
\hline \multirow[t]{2}{*}{2010} & Creche & $6.059 .949,20$ & $4.343 .214,70$ & $4.343 .214,70$ \\
\hline & Pré-escola & & & \\
\hline \multirow[t]{2}{*}{2011} & Creche & $17.488 .814,41$ & $15.722 .592,19$ & $15.541 .792,34$ \\
\hline & Pré-escola & $10.615 .904,41$ & $10.615 .904,41$ & $10.615 .904,41$ \\
\hline \multirow[t]{2}{*}{2012} & Creche & $12.681 .728,43$ & $12.638 .122,75$ & $12.638 .122,88$ \\
\hline & Pré-escola & $10.119 .444,98$ & $10.119 .444,98$ & $10.119 .444,98$ \\
\hline \multirow[t]{2}{*}{2013} & Creche & $28.722 .558,02$ & $19.370 .277,69$ & $17.887 .356,29$ \\
\hline & Pré-escola & $13.771 .111,65$ & $13.771 .111,65$ & $13.771 .111,65$ \\
\hline \multirow[t]{2}{*}{2014} & Creche & $37.576 .567,13$ & $27.836 .450,22$ & $26.860 .443,88$ \\
\hline & Pré-escola & $19.588 .808,06$ & $19.588 .808,06$ & $17.072 .293,45$ \\
\hline \multirow[t]{2}{*}{2015} & Creche & $49.751 .275,07$ & $47.046 .435,15$ & $45.085 .333,44$ \\
\hline & Pré-escola & $40.370 .742,70$ & $40.370 .742,70$ & $40.370 .742,70$ \\
\hline \multirow[t]{2}{*}{2016} & Creche & $23.216 .107,61$ & $22.929 .749,74$ & $21.423 .868,41$ \\
\hline & Pré-escola & $20.944 .948,67$ & $20.943 .777,99$ & $17.072 .943,15$ \\
\hline
\end{tabular}

Fonte: Elaboração dos autores com base nos demonstrativos da função educação no Siope/FNDE. Valores corrigidos pelo INPC de janeiro de 2016.

Cabe ressaltar que, a partir de 2011, o Siope passou a disponibilizar os dados sobre a subfunção educação infantil (365) separadamente entre creche e pré-escola, como podemos verificar na Tabela 7. Esse aspecto é importante, pois obriga os municípios a especificarem melhor os gastos com a educação e, consequentemente, os gastos com a $\mathrm{El}$, os quais sempre ficavam embutidos nos gastos totais e/ou gerais com o ensino, dificultando a compreensão e a análise dos recursos aplicados na educação municipal.

O Proinfância é um dos outros programas onde podemos observar claramente o movimento dos recursos públicos direcionados para a El. De acordo com dados disponíveis no site do FNDE, o município de João Pessoa recebeu, entre os anos de 2013 a 2018, um volume total de $\mathrm{R} \$ 16.790 .979,81$ para a construção de novas escolas de El.

Ao todo, o município de João Pessoa teve proposta aprovada para a construção de 45 unidades; destas, 15 foram concluídas, 28 foram canceladas e duas paralisadas. Os 15 novos Creis construídos significaram algo em torno de 2 mil vagas para crianças de 0 a 3 anos de idade e contribuíram para que o município passasse de 45 Creis, em 2012, para 85, em $2018^{11}$.

11 Como já apontado no texto, João Pessoa tinha, até 2012, 45 Creis; com a municipalização foram transferidas para a rede municipal 27 instituições que estavam sob a responsabilidade da rede estadual, formando um total de 70 instituições, que, somadas às 15 unidades construídas com o Proinfância, completam 85 creches. Para o atendimento de 4 e 5 anos, em 2018, o município contava com 122 instituições. 
Os Recursos Direcionados às Crianças de 0 a 5 Anos de Idade no Contexto do Fundeb em João Pessoa/PB

Considerando o recorte temporal 2007 a 2016, observamos que houve um aumento dos gastos em MDE com a El, nas despesas do Fundeb com El e nos valores declarados que foram aplicados na Subfunção (365). Tal elevação pode indicar maior atenção e direcionamento de recursos para o segmento 0 a 5 anos de idade, ou que a presença do Fundeb tenha representado mais recursos, seja para a El, seja para o EF. Entretanto, observamos nas tabelas (1, 2 e 3) que, entre 2007 e 2010, a aplicação dos recursos educacionais em João Pessoa foi direcionada quase que $100 \%$ para o EF e que os percentuais de MDE, do Fundeb e da Função Educação aplicados na El se constituíram uma fração ínfima sobre o volume total de recursos aplicados naqueles anos. Esses dados sugerem que, pelo menos nos primeiros anos do Fundeb, a presença da El nesse Fundo não representou estímulo para que o município elevasse a atenção e aplicação de recursos públicos para expandir e assegurar o direito à El.

$\mathrm{Na}$ Tabela 8, abaixo, podemos observar quanto a distribuição dos recursos com a MDE ou com o Fundeb, no município de João Pessoa, significou em termos de gasto aluno ano na El. Considerando os valores de MDE aplicados à El e as matrículas para esse segmento em 2007 , o gasto por aluno ano teria sido de $\mathrm{R} \$ 627,99$. Quando simulamos com os recursos do Fundeb para esse mesmo período, o gasto por aluno ano na El teria sido de $\mathrm{R} \$ 19,84$. Esse valor foi muito inferior ao mínimo nacional definido por aluno de creche no Fundeb, em 2007, que foi de $\mathrm{R} \$ 753,344$, que por sua vez já era muito abaixo do valor definido pelo CAQi em 2005 , que era de $R \$ 3.783,00$.

Tabela 8 - Gasto por aluno ano no MDE e no Fundeb - João Pessoa/PB (2007/2016)

\begin{tabular}{|c|c|c|c|c|}
\hline Ano & & Gasto com MDE & Matrículas & Gasto por aluno \\
\hline 2007 & EI & $\mathrm{R} \$ 5.245 .585,52$ & 8.353 & $\mathrm{R} \$ 627,99$ \\
\hline 2007 & EF & $\mathrm{R} \$ 209.927 .458,66$ & 47.188 & $\mathrm{R} \$ 4.448,75$ \\
\hline 2016 & El & $\mathrm{R} \$ 44.161 .056,28$ & 10.851 & $\mathrm{R} \$ 4.069,77$ \\
\hline 2016 & EF & $\mathrm{R} \$ 333.720 .663,92$ & 37.215 & $\mathrm{R} \$ 8.967,37$ \\
\hline Ano & & Gastos com Fundeb & Matrículas & Gasto por aluno \\
\hline 2007 & El & $\mathrm{R} \$ 165.705,57$ & 8.353 & $\mathrm{R} \$ 19,84$ \\
\hline 2007 & EF & $\mathrm{R} \$ 152.485 .013,72$ & 47.188 & $\mathrm{R} \$ 3.231,44$ \\
\hline 2016 & El & $\mathrm{R} \$ 27.413 .956,40$ & 10.851 & $\mathrm{R} \$ 2.526,40$ \\
\hline 2016 & EF & $168.554 .874,00$ & 37.215 & $\mathrm{R} \$ 4.529,21$ \\
\hline
\end{tabular}

Fonte: Elaboração dos autores com base nos dados do Censo Escolas MEC/INEP/ e RREO/Siope/FNDE. Valores corrigidos pelo INPC de janeiro de 2016.

Já em 2016, o gasto por aluno ano da El em MDE teria sido $\mathrm{R} \$ 4.069,768$ e, no Fundeb, $\mathrm{R} \$ 2.526,40$. Quando comparamos com o valor mínimo no Fundeb para 2015 (R\$ $3.349,27 /$ creche) e CAQi/2015 (R $\$ 10.005,59 /$ creche), percebemos que o gasto por aluno da El em João Pessoa precisa avançar muito. Quanto ao gasto por aluno do EF, os valores são em geral superiores aos gastos com a El.

No entanto, é importante, observar que João Pessoa é um município com forte arrecadação em comparação aos demais municípios da Paraíba, com o maior PIB do estado e um dos maiores da Região Nordeste. Nessas circunstâncias, em razão da forte arrecadação e da diminuição das matrículas no EF, João Pessoa poderia direcionar maior percentual de recursos para a El e, dessa maneira, atuar mais fortemente para melhorar o direito à Educação Infantil, considerando a quantidade de crianças fora da escola, sobretudo do segmento creche, e as necessidades de expansão e de qualidade. 
Os Recursos Direcionados às Crianças de 0 a 5 Anos de Idade no Contexto do Fundeb em João Pessoa/PB

\section{Considerações finais}

$\mathrm{O}$ presente estudo nos possibilita afirmar que o atendimento à $\mathrm{El}$ teve um aumento significativo no município de João Pessoa/PB, uma vez que passou a receber recursos do Fundeb. Os dados mostraram que João Pessoa teve um crescimento de $91,41 \%$ das matrículas, entre 2007 e 2016, passando de 11.501 para 22.014. As matrículas públicas aumentaram 29\%, passando de 8.353 , em 2007, para 10.851, em 2016. Nesse período aconteceu o processo de municipalização da El, com a transferência das matrículas que estavam na rede estadual para a rede municipal, o que fez com que o atendimento municipal mais do que duplicasse. Já o setor privado cresceu $254,61 \%$ no período, saltando de 3.148 para 11.163. Esse crescimento aconteceu quase em sua totalidade no setor com fins lucrativos.

Este estudo demonstrou, também, o aumento dos recursos direcionados para a El no período analisado, seja com relação aos gastos em MDE quanto àqueles relativos aos recursos do Fundeb. A elevação de recursos para a El pode ser percebido na presença e ampliação de recursos via programas, como o Pnae e o Proinfância. Contudo, foi possível observar ainda: que o investimento na $\mathrm{El}$, no período analisado, foi aumentando progressivamente; que, nos primeiros anos do Fundeb (2007 a 2010), os percentuais dos recursos aplicados em El foram ínfimos; e que, apesar da considerável elevação dos recursos para a El, entre 2007 e 2016, as receitas da educação municipal foram gastas, majoritariamente, no $\mathrm{EF}$, que em média recebeu acima de $90 \%$ do total dos recursos, e manteve um elevado gasto aluno ano. Esse cenário não se alterou, mesmo que as matrículas e demandas de El tivessem aumentado, que o quantitativo de matrículas do EF tivesse reduzido, de 47.188 para 37.215, e que o Fundeb tivesse passado a financiar a El.

Por fim, o estudo também nos permitiu observar que, apesar do aumento das matrículas e da presença de mais recursos para El no município de João Pessoa, a taxa de atendimento educacional da população de 0 a 5 anos de idade, em 2016 , foi de apenas $32 \%$, pois existiam mais de 42 mil crianças fora da escola de El, das quais 32.764 com faixa etária de 0 a 3 anos. Desse modo, é preciso ampliar os recursos para o provimento dessa etapa da educação para assegurar a ampliação da taxa de atendimento. A garantia do direito à El, de expansão e melhoria da qualidade desse atendimento, está diretamente ligada à quantidade de recursos públicos que são direcionados para seu financiamento. Por essa razão, mesmo com as limitações do Fundeb, é preciso defender que a El permaneça no Novo Fundeb e que a ampliação dos recursos dessa política tenha como parâmetro o CAQi.

\section{Referências}

ADRIÃO, Theresa; BORGHI, Raquel; DOMICIANO, Cássia Alessandra. Educação Infantil, ensino fundamental: inúmeras tendências de privatização. Retratos da Escola, Brasília, v. 4, n. 7, p. 285-297, 2010. Disponível em: http://retratosdaescola.emnuvens.com.br/rde/articl e/view/87. Acesso em: 10 out. 2019.

BASSI, Marcos Edgar. Financiamento da Educação Infantil em seis capitais brasileiras. Cadernos de Pesquisa, São Paulo, v. 41, n. 142, jan./abr. 2011. Disponível em: http://www.scielo.br/scielo.php?pid=S010015742011000100007\&script=sci_abstract\&tlng=pt. Acesso em: 16 out. 2019. 
Os Recursos Direcionados às Crianças de 0 a 5 Anos de Idade no Contexto do Fundeb em João Pessoa/PB

BRASIL. Constituição da República Federativa do Brasil, de 5 de outubro de 1988. Diário Oficial da República Federativa do Brasil, Brasília, DF, 5 out. 1988. Disponível em: https://www2.senado.leg.br/bdsf/bitstream/handle/id/518231/CF88_Livro_EC91_2016.pdf. Acesso em: 18 out. 2019.

BRASIL. Lei n. 9.394, de 20 de dezembro de 1996. Estabelece as diretrizes e bases da educação nacional. Diário Oficial da União, Brasília, 1996. Disponível em: http://www.p lanalto.gov.br/ccivil_03/leis//9394.htm. Acesso em: 16 out. 2019

BRASIL. Emenda Constitucional n. 53, de 19 de dezembro de 2006. Dá nova redação aos arts. $7^{\circ}, 23,30,206,208,211$ e 212 da Constituição Federal e ao art. 60 do Ato das Disposições constitucionais transitórias. Diário Oficial da União, Brasília, 2006. Disponível em: http://www.planalto.gov.br/ccivil_03/constituicao/Emendas/Emc/emc53.htm. Acesso em: 16 out. 2019.

BRASIL. Lei 11.494 de 20 de junho de 2007. Regulamenta o Fundo de Manutenção e Desenvolvimento da Educação Básica e de Valorização dos Profissionais da Educação. Diário Oficial da República Federativa do Brasil, Brasília, DF. 2007. Disponível em: http://www.planalto.gov.br/ccivil_03/_ato2007-2010/2007/lei//11494.htm. Acesso em: 16 out. 2019.

BRASIL. Instituto Nacional de Estudos e Pesquisas Educacionais Anísio Teixeira. Censo Escolar da Educação Básica 2013: resumo técnico. Brasília: Inep, 2014. Disponível em: http://download.inep.gov.br/educacao_basica/censo_escolar/resumos_tecnicos/resumo_tecn ico_censo_educacao_basica_2013.pdf. Acesso em: 16 out. 2019.

BRASIL. Instituto Nacional de Estudos e Pesquisas Educacionais Anísio Teixeira. Plano Nacional de Educação PNE 2014-2024: Linha de Base. Brasília, DF: Inep, 2015. 404 p. Disponível em: http://portal.inep.gov.br/documents/186968/485745/Plano+Nacional +de+Educa\%C3\%A7\% C3\%A3o+PNE+2014-2024++Linha+de+Base/c2dd0faa-7227-40eea520-12c6fc77700f?version=1.1. Acesso em: 10 out. 2019.

BRASIL. Instituto Nacional de Estudos e Pesquisas Educacionais Anísio Teixeira. Relatório de Monitoramento do $1^{\circ}$ Ciclo das Metas no Plano Nacional de Educação: biênio 20142016. Brasília: Inep, 2016. Disponível em: http://portal.inep.gov.br/documents/186968/4 85745/RELAT\%C3\%93RIO+DO+PRIMEIRO+CICLO+DE+MONITORAMENTO+DAS+META S+DO+PNE+-+BI\%C3\%8ANIO+2014-2016/0dc50e21-3a60-444b-b7f6-

1f16b8e5591f?version=1.1. Acesso em: 10 out. 2019.

BRASIL. Ministério da Transparência e Controladoria-Geral da União. Secretaria Federal de Controle Interno. Relatório de Avaliação da Execução de Programa de Governo $\mathbf{N}^{\circ} \mathbf{8 0}$ Implantação de Escolas para Educação Infantil. Brasília, 2017.

BRASIL. INEP. Instituto Nacional de Estudos e Pesquisas Educacionais Anísio Teixeira. Panorama da Educação: destaques do Education at a Glance 2018. Brasília: Inep, 2018a. Disponível em: http://download.inep.gov.br/acoes_internacionais/eag/documentos/2018/Pan orama_da_Educacao_2018_do_Education_a_glance.pdf. Acesso em: 10 out. 2019.

BRASIL. A Meta 1 do Plano Nacional de Educação 2014-2024 (Educação Infantil). Relatório de Avaliação de Políticas Públicas. Comissão de Educação, Cultura e Esporte do Senado 
Os Recursos Direcionados às Crianças de 0 a 5 Anos de Idade no Contexto do Fundeb em João Pessoa/PB

Federal. Brasília, 2018b. Disponível em: http://www.mieib.org.br/wp-content/uploads/ 2018/12/RELAT\%C3\%93RIO_FINAL.S-632018-CE-20181211_.pdf. Acesso em: 10 out. 2019.

BRASIL. INEP. Instituto Nacional de Estudos e Pesquisas Educacionais Anísio Teixeira. Censos Educacionais. Sinopses Estatísticas da Educação Básica. Brasília, 2019. Disponíveis em: http://www.inep.gov.br/. Acesso em: 10 out. 2019.

CAMPANHA Nacional pelo Direito à Educação. Plano Nacional de Educação: 5 anos de Descumprimento. Análise da execução dos artigos, metas e estratégias da Lei $n^{\circ}$ 13.005/2014. Relatório metas e estratégias do Plano Nacional de Educação. 2019. Disponível em: https://campanha.org.br/acervo/relatorio-de-metas-do-plano-nacional-deeducacao-2019/. Acesso em: 10 out. 2019.

CAMPOS, Maria Malta. Atendimento à infância na década de 80: as políticas federais de financiamento. Cadernos de Pesquisa, São Paulo, Fundação Carlos Chagas, n. 82, p. 5-20, ago. 1992. Disponível em: http://publicacoes.fcc.org.br/ojs/index.php/cp/article/view/978. Acesso em: 10 out. 2019.

CAMPOS, Maria Malta; ROSEMBERG, Fúlvia; FERREIRA, Isabel M. Creches e Pré-Escolas no Brasil. 3. ed. São Paulo: Cortez, 2001.

CAMPOS, Maria Malta; FÜLLGRAF, Josete; WIGGERS, Verena. A Qualidade da educação infantil brasileira: alguns resultados de pesquisa. Cadernos de Pesquisa, São Paulo, v. 36, n. 127, p. 87-128, jan./abr. 2006. Disponível em: http://www.scielo.br/scielo.php?pid=S010015742006000100005\&script=sci_abstract\&tlng=pt. Acesso em: 11 out. 2019.

DIDONET, Vital. A Educação Infantil na Educação Básica e o FUNDEB. In: FUNDEB. Avanços na universalização da Educação Básica. Brasília: Inep, 2006. p. 21-30.

JOÃO PESSOA. Plano de Governo da Cidade de João Pessoa 2013-2016. João Pessoa: Prefeitura Municipal, 2013. Disponível em: https://www.nossasaopaulo.org.br/portal/ arquivos/programasdemetas/plano-de-metas-joao-pessoa-2013-2016.pdf. Acesso em: 11 out. 2019.

KRAMER, Sônia. A política do pré-escolar no Brasil: a arte do disfarce. 7. ed. São Paulo: Cortez, 2003.

KUHLMANN JUNIOR, Moysés. Instituições Pré-Escolares Assistencialistas no Brasil (18991922). Cadernos de Pesquisa, São Paulo, Fundação Carlos Chagas, n. 78, ago. 1991. Disponível em: http://publicacoes.fcc.org.br/ojs/index.php/cp/article/view/1027. Acesso em: 16 out. 2019.

PEREIRA, Maria Aparecida Nunes. Financiamento da educação básica no Estado da Paraíba: análise dos primeiros resultados do FUNDEB nos municípios de João Pessoa e Cabedelo-PB. 2012. Tese (Doutorado em Educação) - Universidade Estadual de Campinas, Campinas, 2012. Disponível em: http://www.repositorio.unicamp.br/handle/REPOSIP/250871. Acesso em: 10 out. 2019.

PINTO, José Marcelino Rezende. A política recente de fundos para o financiamento da educação e seus efeitos no pacto federativo. Educação \& Sociedade, Campinas, v. 28, n. 
Os Recursos Direcionados às Crianças de 0 a 5 Anos de Idade no Contexto do Fundeb em João Pessoa/PB

100, 2007. Disponível em: http://www.scielo.br/scielo.php?pid=S01017330200700030001 2\&script=sci_abstract\&tIng=pt. Acesso em: 10 out. 2019.

PINTO, José Marcelino de Rezende. O Financiamento da educação na Constituição Federal de 1988: 30 anos de mobilização social. Educação \& Sociedade, Campinas, v. 39, n. 145, 2018. Disponível em: http://www.scielo.br/scielo.php?script=sci_abstract\&pid=S01017330 $2018000400846 \&$ Ing=pt\&nrm=iso. Acesso em: 10 out. 2019.

SANTOS, Joedson Brito dos. Uma investigação sobre o financiamento da educação infantil no contexto do Fundeb: entre limites e contradições da expansão do atendimento às crianças de 0 a 6 anos de idade em João Pessoa/PB. 2015. Tese (Doutorado em Educação) - Universidade Federal da Paraíba, João Pessoa, 2015.

SOUSA JUNIOR, Luiz de. No meio da travessia: breves narrativas sobre gestão municipal da educação. João Pessoa: Editora do CCTA, 2017.

Joedson Brito Santos é graduado em Pedagogia pela Universidade Estadual de Santa Cruz (UESC), mestre em Educação pela Universidade Federal da Bahia (UFBA) e doutor em Educação pela Universidade Federal da Paraíba (UFPB). Atualmente é professor Adjunto II da Universidade Federal do Tocantins UFT, realiza o Estágio Pós-doutoral na Universidade de São Paulo (USP) e coordena o Grupo de Estudos e Pesquisas em Política e Prática Educativa (Gepppe). É Coordenador Científico e membro do Núcleo de Estudos e Pesquisa em Educação, Desigualdade Social e Políticas Públicas (Neped) e atua como pesquisador no Programa Educação, Pobreza e Desigualdade Social da UFT/MEC/Secadi.

ORCID: http://orcid.org/0000-0003-4394-9294

E-mail: jbsantus.ufpb@gmail.br

Luiz de Sousa Junior obteve a graduação em Ciências Econômicas pela Universidade Federal da Paraíba (1988), o mestrado em Educação pela Universidade Federal da Paraíba (1994) e o doutorado em Educação pela Universidade de São Paulo (2003). Foi professor Associado da Universidade Federal da Paraíba. Exerceu a função de chefe de gabinete do reitor da UFPB no período de novembro de 2004 a setembro de 2012. Foi secretário municipal de educação do município de João Pessoa no período de setembro de 2012 a dezembro de 2014. Foi avaliador da pós-graduação da Coordenação de Aperfeiçoamento de Pessoal de Nível Superior (CAPES) na área de educação e coordenador de programas profissionais da área de Educação da CAPES.

ORCID: http://orcid.org/0000-0002-5646-941X

E-mail: luizsjunior@gmail.com 


\section{Editores do volume 11}

Márcia Aparecida Jacomini - Universidade Federal de São Paulo, Brasil

José Marcelino de Rezende Pinto - Universidade de São Paulo, Brasil

\section{Comitê Editorial}

Nalú Farenzena - Universidade Federal do Rio Grande do Sul, Brasil

Juca Gil - Universidade Federal do Rio Grande do Sul, Brasil

Theresa Adrião - Universidade Estadual de Campinas, Brasil

Ângelo Ricardo de Souza - Universidade Federal do Paraná, Brasil

\section{Conselho Editorial}

\section{Alejandro Morduchowicz}

Universidad Pedagógica, Provincia de Buenos Aires, Argentina

Andréa Barbosa Gouveia

Universidade Federal do Paraná, Brasil

Fernanda Saforcada

Universidade de Buenos Aires, Argentina

Jacques Velloso

Universidade de Brasília, Brasil

João Monlevade

Senado Federal, Brasil

Jorge Abrahão de Castro

Instituto de Pesquisa Econômica Aplicada / IPEA, Brasil

Lisete Regina Gomes Arelaro

Universidade de São Paulo, Brasil

Luis Carlos Sales

Universidade Federal do Piauí, Brasil

Luiz de Sousa Junior

Universidade Federal da Paraíba, Brasil

Luiz Fernandes Dourado

Universidade Federal de Goiás, Brasil

Magna França

Universidade Federal do Rio Grande do Norte, Brasil

Marcos Edgar Bassi

Universidade Federal de Santa Catarina, Brasil

Maria Angélica Pedra Minhoto

Universidade Federal de São Paulo, Brasil

Maria Beatriz Luce

Universidade Federal do Rio Grande do Sul, Brasil

Maria Dilnéia Espíndola Fernandes

Universidade Federal de Mato Grosso do Sul, Brasil

Nelson Cardoso do Amaral

Universidade Federal de Goiás, Brasil

Nicholas Davies

Universidade Federal Fluminense, Brasil

Robert E. Verhine

Universidade Federal da Bahia, Brasil

Romualdo Portela de Oliveira

Universidade de São Paulo, Brasil

Rosana Gemaque Rolim

Universidade Federal do Pará, Brasil

Rubens Barbosa de Camargo

Universidade de São Paulo, Brasil

Theresa Adrião

Universidade Estadual de Campinas, Brasil

Tristan McCowan

University of London, Reino Unido

Vera Jacob

Universidade Federal do Pará, Brasil

Vera Peroni

Universidade Federal do Rio Grande do Sul, Brasil

Vitor Henrique Paro

Universidade de São Paulo, Brasil

\section{Equipe editorial}

Apoio ao Comitê Editorial: Caio Cabral da Silva

Diagramação, Revisão de português e normalização: Edson Leonel de Oliveira

Revisão de inglês: Sabrina Ferreira

Fineduca - Revista de Financiamento da Educação

Associação Nacional de Pesquisa em

Financiamento da Educação

e-mail: revista.fineduca@gmail.com | site: http://seer.ufrgs.br/fineduca 